
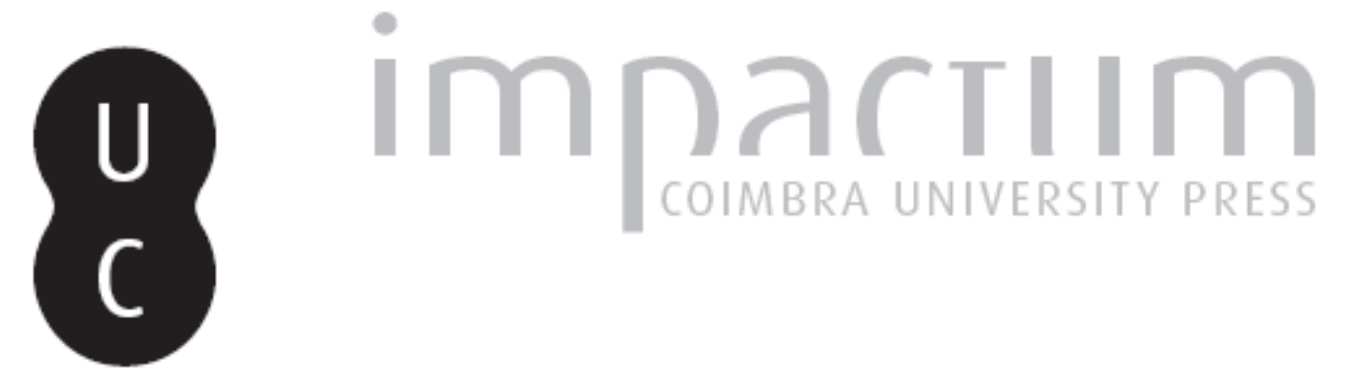

\title{
Evolução recente dos recursos hídricos superficiais em 4 cursos de água tributários do Rrio Douro
}

\author{
Autor(es): $\quad$ Nunes, Adélia
}

Publicado por: Associação Portuguesa de Riscos, Prevenção e Segurança

URL persistente:

URI:http://hdl.handle.net/10316.2/36195

DOI:

DOI:http://dx.doi.org/10.14195/1647-7723_15_3

Accessed : $\quad$ 26-Apr-2023 09:56:59

A navegação consulta e descarregamento dos títulos inseridos nas Bibliotecas Digitais UC Digitalis, UC Pombalina e UC Impactum, pressupõem a aceitação plena e sem reservas dos Termos e Condições de Uso destas Bibliotecas Digitais, disponíveis em https://digitalis.uc.pt/pt-pt/termos.

Conforme exposto nos referidos Termos e Condições de Uso, o descarregamento de títulos de acesso restrito requer uma licença válida de autorização devendo o utilizador aceder ao(s) documento(s) a partir de um endereço de IP da instituição detentora da supramencionada licença.

Ao utilizador é apenas permitido o descarregamento para uso pessoal, pelo que o emprego do(s) título(s) descarregado(s) para outro fim, designadamente comercial, carece de autorização do respetivo autor ou editor da obra.

Na medida em que todas as obras da UC Digitalis se encontram protegidas pelo Código do Direito de Autor e Direitos Conexos e demais legislação aplicável, toda a cópia, parcial ou total, deste documento, nos casos em que é legalmente admitida, deverá conter ou fazer-se acompanhar por este aviso.

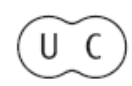




\section{territorium}

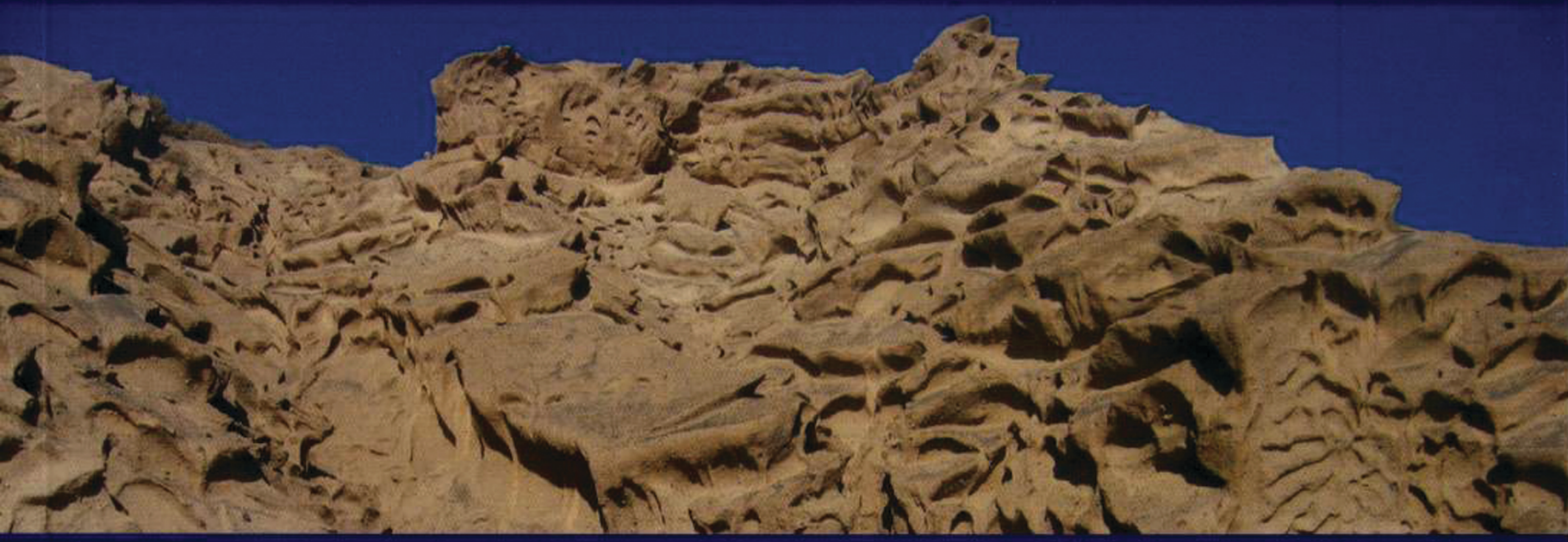

15

Revista da Associação Portuguesa de Riscos, Prevenção e Segurança 2008 
pp. $29-38$

\title{
EVOLUÇÃO RECENTE DOS RECURSOS HÍDRICOS SUPERFICIAIS EM 4 CURSOS DE ÁGUA TRIBUTÁRIOS DO RIO DOURO.
}

\author{
Adélia Nunes \\ adelia.nunes@ci.uc.pt \\ Professora Auxiliar, Instituto de Estudos Geográficos \\ Faculdade de Letras, Universidade de Coimbra
}

\begin{abstract}
RESUMO
No presente trabalho analisa-se a evolução dos recursos hídricos superficiais em quatro cursos de água, tributários do rio Douro, desde a segunda metade do século XX até aos primórdios do XXI. Os resultados obtidos mostram uma diminuição no escoamento total anual dos 4 rios, embora em nenhum dos casos esse decréscimo seja estatisticamente significativo. Essa tendência declinante é, particularmente, marcante após 1980.

Com excepção do Outono, que verifica um ligeiro incremento, todas as outras épocas do ano manifestam tendências regressivas nos escoamentos observados, mais relevantes no Inverno e na Primavera, embora no Verão, devido à acentuada estiagem manifestada por estes rios, possam ocorrer situações de elevada precariedade em termos de recursos hídricos. Esta diminuição dos recursos, sobretudo nos períodos em que se regista um máximo de procura e um mínimo em termos de disponibilidade, deverá constituir matéria de reflexão de modo a evitar situações de insuficiência de água.
\end{abstract}

Palavras-chave: Recursos hídricos, variações espácio-temporais, tributários do rio Douro.

\section{RÉSUMÉ}

Nous analysons, dans cette étude, l'évolution des ressources hydriques superficielles dans quatre cours d'eau, tributaires du Douro, depuis la seconde moitié du XXème siècle jusqu'au début du XXlème siècle. Les résultats obtenus montrent une diminution de l'écoulement total annuel de ces quatre cours d'eau, bien que cette baisse ne soit statistiquement significative dans aucun des cas examinés. Cette tendance déclinante est tout particulièrement visible après 1980.

Excepté en automne, saison pendant laquelle on constate une légère augmentation, toutes les autres périodes de l'année révèlent des tendances régressives dans les écoulements observés, plus évidentes en hiver et au printemps, même si en été, en raison d'un fort étiage, manifesté dans ces cours d'eau, des situations de grande précarité en ce qui concerne les ressources hydriques peuvent se produire. Cette diminution des ressources, surtout dans les périodes où on enregistre une plus grande demande alors que les réserves d'eau sont au plus bas, devra fournir matière à réflexion de façon à éviter des situations de pénurie d'eau.

Mots-clés: Ressources hydriques, variations spatio-temporelles, tributaires du Douro.

\begin{abstract}
In this work we analyze the surface water resources evolution in four stream flows, tributaries of the Douro river, since the second half of the XX century till the beginning of the XXI. The obtained results show a decrease in the total annual flow of the four rivers, even though this decrease was not statistically significant. This declining tendency is particularly remarkable after 1980.

Except for autumn, in which a slight increase is verified, all the other seasons show regressive tendencies in overland flow, much more accentuated during winter and spring, although in summer, due to the deficit shown by these rivers, situations of high amount scarcity in water resources could be promoted. This annual decline in water resources, especially during the period in which the highest demand and the lowest quantity are registered, must be a subject for reflection, in order to avoid situations of water scarcity.
\end{abstract}

Key - words: Hydro-resources, temporal and spatial variation, tributaries of Douro river 


\section{Introdução}

Apesar de Portugal não ser um país pobre em recursos hídricos (CUNHA et al., 2006), a sua disponibilidade varia substancialmente no espaço e no tempo. Por conseguinte, uma eficiente gestão deverá garantir um pleno abastecimento à população bem como às suas actividades, directamente dependentes dos recursos hídricos. Apesar das preocupações com a eficaz gestão da água terem vindo a aumentar em Portugal, a par de uma crescente regulamentação dos recursos hídricos, é recorrente a existência de problemas de planificação que conduzem à falta de água, como os que se produziram na Primavera/Verão de 2005 e até mesmo no Outono/Inverno de 2007, os quais afectaram vastas regiões do país, incluindo as áreas mais húmidas.

Por outro lado, existe um consenso científico em torno da ocorrência de importantes mudanças ao nível climático e, nestes últimos anos, são múltiplas as investigações que se debruçam sobre a respectiva incidência espacial e efeitos à escala planetária. $\mathrm{Na}$ Europa, os países da bacia mediterrânea são os que apresentam maior susceptibilidade às mudanças ambientais, com reflexo ao nível dos recursos hídricos, solo e vegetação (PARRY, 2000; AyalaCARCEDO, 2000; IPCC, 2001).

Segundo CunHa et al. (2006) devido à estreita relação entre os fenómenos climáticos e os recursos hídricos são previsíveis impactos na sua disponibilidade total, distribuição espacial e temporal das águas superficiais e subterrâneas, na humidade do solo, nas condições de ocorrência de cheias e de secas, na qualidade da água, nos regimes de erosão, transporte e deposição, nas condições ecológicas dos rios e estuários e na procura de água.

Perante estas circunstâncias, a avaliação dos recursos hídricos superficiais e as previsões sobre a sua possível evolução requer como ponto de partida a análise das séries de caudais existentes, com o intuito de valorizar a sua disponibilidade final para assegurar a sustentabilidade dos agro-sistemas (MACHÍn et al., 2005).

Devido ao crescente interesse por este tipo de estudo, no intuito de conhecer a evolução dos caudais, em regime natural, o presente trabalho tem como objectivos analisar e confrontar as variações espaciais e a evolução temporal de séries de caudais em 4 bacias, com diferentes áreas de drenagem e quantitativos médios de precipitação. Optou-se por estes cursos de água, tributários das margens direita e esquerda do Rio Douro por disporem de séries de dados já, consideravelmente, longas e também porque não foram afectados por nenhuma obra relevante de regularização, portanto, os respectivos comportamentos podem ser considerados representativos do regime natural.

\section{Material e métodos}

\section{1. Área de estudo}

A localização geográfica dos cursos de água estudados encontra-se na figura 1, enquanto as principais características das respectivas bacias sistematizam-se no quadro I. A sua observação mostra que as bacias em análise apresentam áreas de drenagem bastante díspares, compreendidas entre os $330 \mathrm{~km}^{2}$ e os $3800 \mathrm{~km}^{2}$. Os rios Beça e Sabor, respectivamente, com a maior e a menor área drenada, são tributários da margem direita do Douro, enquanto os rios Massueime e Águeda são da margem esquerda (Figura 1).

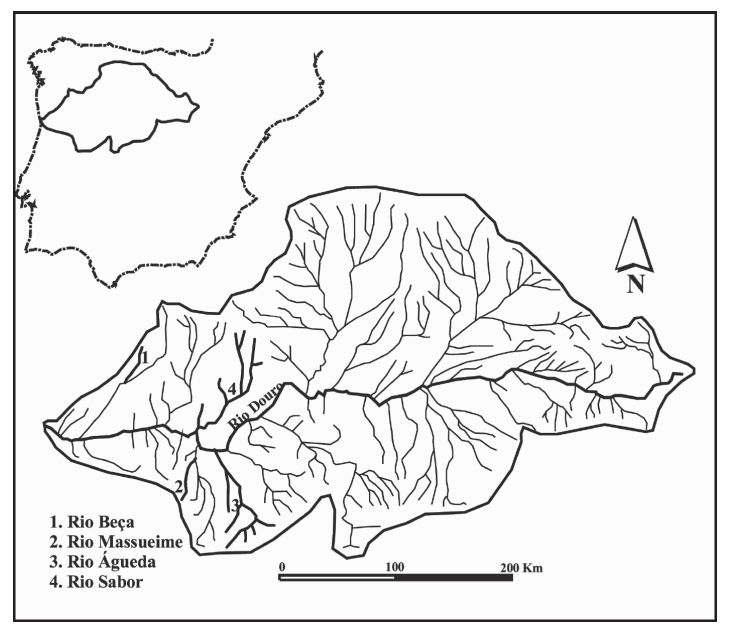

Figura 1 - Localização geográfica dos cursos de água estudados.

Todas se integram no Maciço Hespérico, caracterizado, no essencial, por apresentar um substrato lítico antemesozóico, constituído por rochas metassedimentares ou granitóides, de permeabilidade reduzida, aqui e além cobertas por rochas detríticas mais recentes, em regra cenozóicas. Embora alternando no espaço, os afloramentos xistentos dominam junto ao Douro, enquanto os afloramentos graníticos predominam na Meseta. Os depósitos de cobertura mais recentes acham-se, no fundamental, confinados a áreas abatidas tectonicamente e formam uma cobertura, mais ou menos, contínua na Meseta espanhola. 
Quadro I - Principais características das bacias hidrográficas em estudo.

\begin{tabular}{|c|c|c|c|c|c|}
\hline & $\begin{array}{c}\text { Área total } \\
\text { da bacia } \\
\left(\mathbf{k m}^{2}\right)\end{array}$ & Nascente & $\begin{array}{c}\text { Escoamento médio } \\
\left.\text { anual (dam }{ }^{3}\right) \\
(1960-2000)^{(3)}\end{array}$ & $\begin{array}{c}\text { Escoamento médio } \\
\text { anual } / \mathrm{km}^{2} \\
\left(\mathrm{dam}^{3}\right)^{(3)}\end{array}$ & $\begin{array}{c}\text { Precipitação } \\
\text { média anual (mm) } \\
(1960-90)^{(4)}\end{array}$ \\
\hline $\begin{array}{c}\text { Rio Beça } \\
\text { (afluente do rio Tâmega) }\end{array}$ & 337,29 & Serra do Barroso & 295632 & 876,45 & $1200-2000$ \\
\hline $\begin{array}{l}\text { Rio Massueime } \\
\text { (afluente do rio (ôa) }\end{array}$ & 405,4 & Junto à Guarda & 81142 & 200,2 & $400-800$ \\
\hline Rio Águeda & $2537,08^{(1)}$ & $\begin{array}{l}\text { Serra das Mesas } \\
\text { (Espanha) }\end{array}$ & 500275 & 197,2 & $400-1600$ \\
\hline Rio Sabor & $3868,31^{(2)}$ & $\begin{array}{l}\text { Serra de Montesinho } \\
\text { (Espanha) }\end{array}$ & 976707 & 280,1 & $500-1600$ \\
\hline
\end{tabular}

(1) Da área total, só $249,15 \mathrm{~km}^{2}$ se integram em território português. (2) Da área total, 555,57 km² localizam-se em Espanha.

(3) Valores calculados com base nos pontos de monitorização referidos no quadro II. (4) Com base na carta de distribuição da precipitação média anual, Atlas do Ambiente (www.iambiente.pt)

Se exceptuarmos o rio Beça, que pelo facto de drenar os contrafortes da Serra do Barroso e, por conseguinte, registar os maiores quantitativos de precipitação e os maiores coeficientes de escoamento (cerca de 4 vezes superiores quando comparados com os rios Massueime e Águeda e 3 vezes mais elevados face ao rio Sabor) (quadro I), as outras bacias hidrográficas encontram-se abrigadas face às montanhas do Norte e Centro Ocidental de Portugal. Esta posição de abrigo, relativamente à acção das massas de ar provenientes do Atlântico, explica os menores quantitativos de precipitação, apenas intensificados nas áreas de maior altitude, e os inferiores escoamentos comparativamente à rede fluvial do Litoral Centro e, em especial, do litoral Norte português.

O regime fluvial dos cursos de água analisados, apesar da enorme diferenciação em termos de superfície drenada e dos distintos coeficientes de escoamento evidenciados, caracteriza-se por fortes variações intra e interanuais, como reflexo do comportamento irregular das precipitações, tipicamente mediterrâneas (Figura 2). Assim, sazonalmente, todos os cursos de água comportam duas épocas contrastadas, com características opostas; uma marcada pela abundância de recursos hídricos, a qual coincide com o período de maiores quantitativos de precipitação, normalmente de Outubro a Junho; a outra de escassez hídrica, caracterizada por reduzidas precipitações, entre Julho e Setembro. Esta última corresponde, à estação com maiores exigências em termos hídricos, tanto para consumo da população como para fins agrícolas e turísticos.

Os maiores escoamentos ocorrem nos meses de Dezembro a Março, devido às precipitações líquidas de carácter frontal, associados à passagem de perturbações frontais de Oeste, típicas das nossas latitudes. Por outro lado, nesta altura do ano, normalmente, os solos já se encontram saturados ou próximos do ponto de saturação, exportando, assim, grande parte da precipitação sob a forma de escoamento. Posteriormente, os caudais vão descendo até aos meses de Verão, nos quais se assinalam valores de escoamento muito baixos ou até mesmo nulos, em anos de maior escassez pluviométrica. Com efeito, o regime irregular das precipitações do clima Mediterrâneo é o principal responsável pelo comportamento dos caudais, imprimindo-lhe comportamentos fortemente contrastados.

Nestas circunstâncias, a gestão da água torna-se um factor-chave que afecta tanto a sua quantidade como a sua qualidade. Desde o ponto de vista técnico, deve garantir-se o abastecimento urbano mais os sectores como o turismo e a agricultura.

\subsection{Metodologia}

Os parâmetros relativos ao escoamento foram extraídos do Sistema Nacional de Informação de Recursos Hídricos (SNIRH) do Instituto da Água (INAG), para a segunda metade do século XX e princípios do XXI (Quadro II). Os dados disponibilizados por esta Instituição incluem os escoamentos totais anuais e mensais $\left(\mathrm{em} \mathrm{dam}^{3}\right)$ e as médias diárias de escoamento $\left(\mathrm{em} \mathrm{m}^{3} / \mathrm{s}\right)$.

Na análise hidrológica das diferentes bacias estudouse a evolução temporal das contribuições anuais e mensais e expressou-se, graficamente, a tendência observada para os períodos analisados. Para contrastar o grau de significado das tendências 

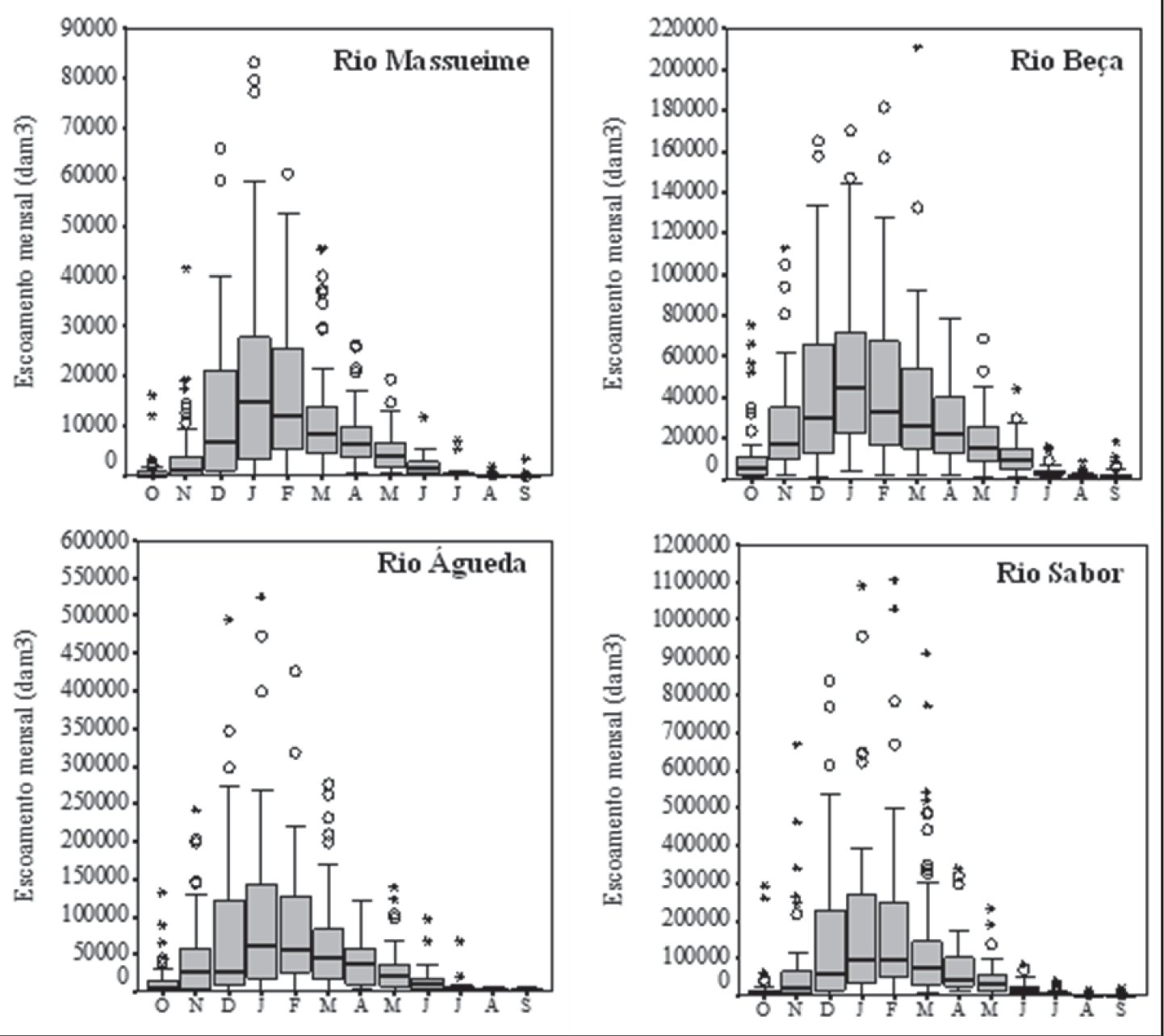

Figura 2 - Mediana, valores correspondentes aos quartis 25 e 75 e valores extremos para os meses do período hidrológico analisado, nos diferentes postos hidrométricos.

(positiva, negativa ou nula) com um determinando nível de confiança, aplicaram-se testes não paramétricos como o coeficiente $\rho$ de Spearman, recomendado por vários autores (SNEYERS, 1992; YUE et al., 2002). Este coeficiente não é sensível a assimetrias na distribuição, nem à presença de outliers, não exigindo, portanto, que os dados provenham de duas populações normais. $O$ coeficiente $\rho$ de Spearman varia entre 1 e -1. Quanto mais próximo estiver destes extremos, maior será a associação, directa ou inversa, entre as variáveis. Como indicador da variação de caudais em regimes fluviais pode analisar-se a frequência de dias em que se supera um determinado limiar. Estes limiares são de grande utilidade para definir eventos, como por exemplo caudais de cheia, tendo sido utilizados por diversos autores (GARCíA-RUIz et al., 2001; LóPEZ MORENO et al., 2003; MACHín et al., 2005). Neste caso determinaram-se os dias com caudais 10 vezes superiores e 10 vezes inferiores à média.

Quadro II - Dados relativos às estações hidrométricas utilizadas neste estudo.

\begin{tabular}{|c|c|c|c|c|}
\hline & $\begin{array}{c}\text { Estação hidrométrica } \\
\text { de referência }\end{array}$ & Área drenada $\left.\mathbf{( k m}^{2}\right)$ & $\begin{array}{c}\text { Período } \\
\text { analisado }\end{array}$ & $\begin{array}{c}\mathbf{N}^{\circ} \text { de } \\
\text { anos }(\boldsymbol{n})\end{array}$ \\
\hline $\begin{array}{c}\text { Rio Beça } \\
\text { (afluente do rio Tâmega) }\end{array}$ & $\begin{array}{c}\text { Cunhas } \\
\text { (Ribeira de Pena/V. Real) }\end{array}$ & 337,29 & $1950 / 51-2003 / 04$ & 47 \\
\hline $\begin{array}{c}\text { Rio Massueime } \\
\text { (afluente do rio Côa) }\end{array}$ & $\begin{array}{c}\text { Vale Trevo } \\
\text { (Pinhel/Guarda) }\end{array}$ & 405,4 & $1957 / 58-2003 / 04$ & 54 \\
\hline Rio Águeda & $\begin{array}{c}\text { Escalhão } \\
\text { (F.C. Rodrigo/Guarda) }\end{array}$ & 2537,08 & $1958 / 59-2004 / 05$ & 47 \\
\hline Rio Sabor & $\begin{array}{c}\text { Qt. das Laranjeiras (Torre de } \\
\text { Moncorvo/Bragança) }\end{array}$ & 3487,5 & $1950 / 51-2005 / 06$ & 56 \\
\hline
\end{tabular}


Um outro método utilizado para melhor compreender a distribuição dos caudais baseia-se na sua ordenação por quartis e/ou percentis (LóPEZ MORENO, 2003). Assim, depois de determinados os limiares para cada uma das classes de percentis, referentes às quatro linhas de água, procedeu-se à quantificação da distribuição dos caudais. Esta classificação dá informação sobre se um reduzido número de dias se caracteriza por elevados caudais ou se, pelo contrário, o regime dos rios assinala caudais reduzidos, por largos períodos de tempo.

\section{Análise e discussão dos resultados}

\section{1. Evolução anual, mensal e sazonal dos caudais}

Os gráficos que se apresentam na sequência (Figura 3) mostram os valores anuais de escoamento e a respectiva tendência evolutiva, desde a década de 50 do passado século até aos princípios da actual centúria. Através da sua análise é possível confirmar a forte variabilidade interanual dos caudais, em todas as bacias estudadas, sendo ainda de destacar a trajectória similar das respectivas curvas, sugerindo que os quatro cursos de água apresentam comportamentos hidrológicos praticamente idênticos. Em todos os rios, o valor máximo de escoamento anual ocorreu no ano hidrológico de 2000/01 enquanto os mínimos não apresentam coincidência temporal.

Quadro III - Variações no escoamento total anual.

\begin{tabular}{|c|c|}
\hline Bacia & $\begin{array}{c}\text { Variações no escoamento } \\
\text { total anual (\%) }\end{array}$ \\
\hline Rio Beça (1950/51-2004/05) & $-26,5$ \\
\hline Rio Massueime (1957/58-2004/05) & $-22,5$ \\
\hline Rio Águeda (1957/58-2004/05) & $-28,0$ \\
\hline Rio Sabor (1950/51-2005/06) & $-25,2$ \\
\hline
\end{tabular}

A análise à tendência evolutiva dos respectivos totais anuais mostra-se regressiva em todos os rios, embora em nenhum dos casos observados essa diminuição seja significativa em termos estatísticos $(p>0,05)$. A quantificação dessas perdas após os anos 50 do passado século mostra, no entanto, valores bastante importantes, a oscilar entre os $22,5 \%$ no rio Massueime e os $28 \%$ no rio Águeda (Quadro III). Esta tendência declinante nos recursos hídricos superficiais está de acordo com o identificado por NUNES (2007), para o rio Côa, por Ceballos Barbancho \& Morán Tejeda (2006), para as cabeceiras do rio Tormes, e por MACHín et al. (2005), para o rio Arlanza, igualmente afluentes do Douro. Nos Pirenéus, García-Ruiz et al. (2001) e BEGUERIA et al. (2003) também estimaram reduções de cerca de $30 \%$ no escoamento das bacias de cabeceira, entre 1945-1990. Perante estas circunstâncias, poderá esboçar-se um padrão, mais ou menos generalizado, a toda a Península lbérica.
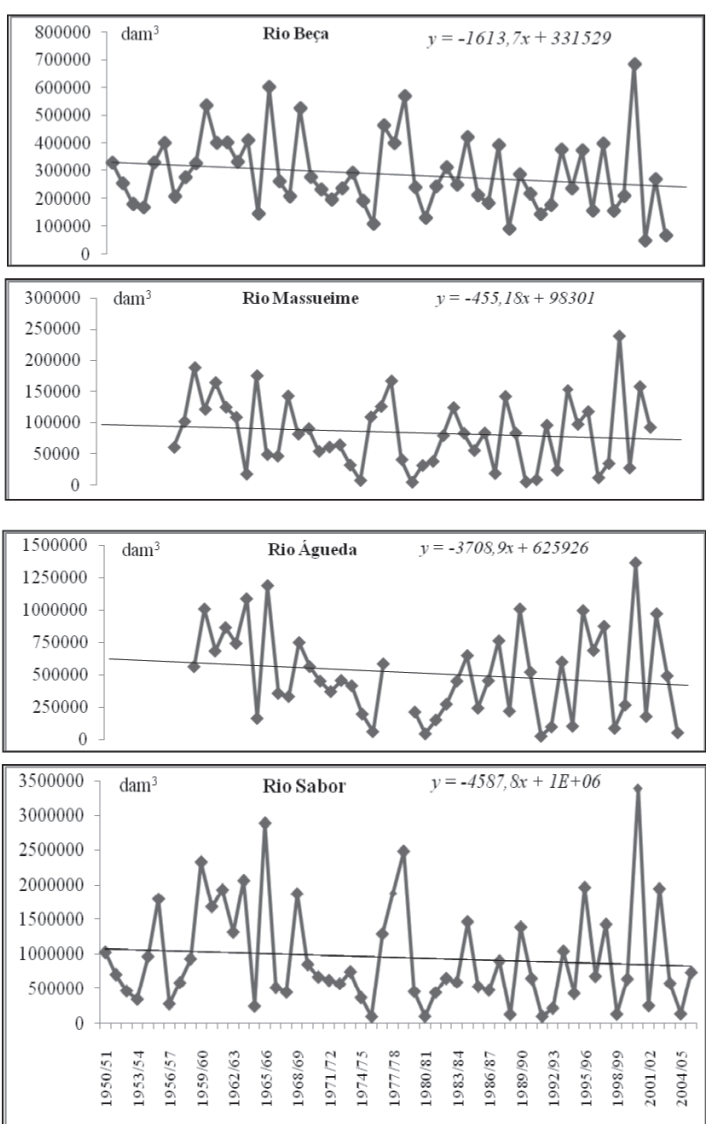

Figura 3. Evolução interanual do caudal dos rios Beça, Massueime, Águeda e Sabor.

A evolução mensal dos escoamentos fluviais apresenta, no essencial, comportamentos similares (Figura 4). De um modo geral, os meses de Outono assinalam ligeiros incrementos nos respectivos valores de escoamento, apesar de em nenhum dos casos esse aumento se revelar significativo em termos estatísticos. Os restantes meses registam, sistematicamente, reduções nos respectivos totais escoados, sendo Fevereiro e Março os que assinalam as maiores perdas, as quais se manifestam, em todas as bacias, estatisticamente significativas $(p<0,05)$.

No período de estiagem, observa-se igualmente uma diminuição nos caudais, que se poderá revelar verdadeiramente desastrosa, na eventualidade de se vrificarem algumas das tendências previstas para a Península lbérica, de aumento da temperatura e quebra da precipitação, nesta época do ano.

A análise ao escoamento sazonal médio em cada uma das estações hidrométricas, tal como se pode 


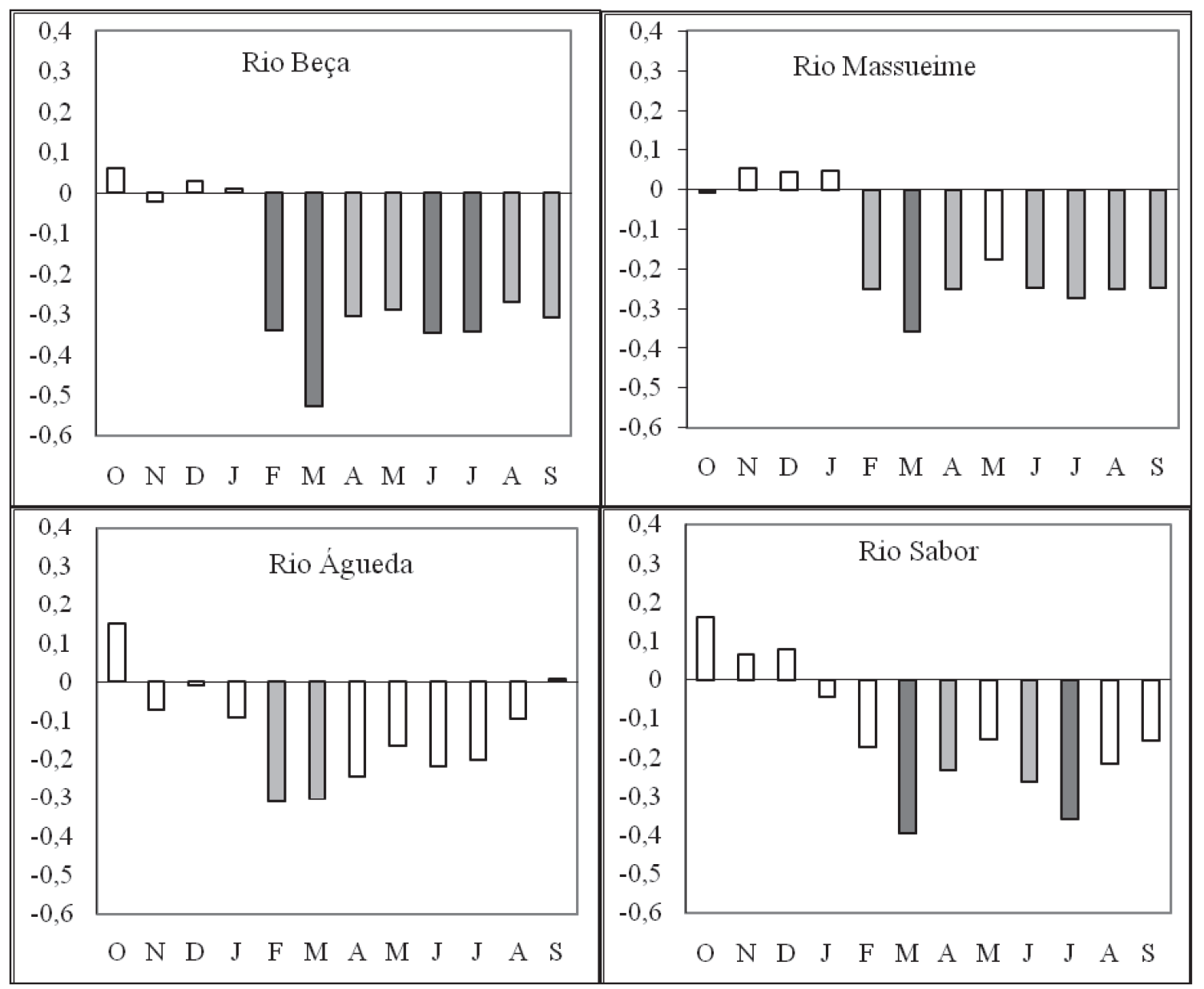

Figura 4 - Análise das séries mensais mediante a aplicação do coeficiente de Spearman

(As correlações significativas para um nível de confiança $p<0,01$ e $p<0,05$ encontram-se representadas, respectivamente, pelo cinza escuro e cinza claro).

observar na figura 5, mostra diferenças bastante relevantes se distinguirmos dois períodos, o primeiro compreendido entre 1950 e 1980 e o segundo entre 1980 e $2004-05$ ou $2005 / 06$ conforme os casos.

Assim, em todos os rios se assinalam incrementos, na respectiva média, no período de Outono, quando confrontadas as décadas de 50,60 e 70 com as de 80 e 90 do passado século e inícios deste novo milénio. Os respectivos acréscimos oscilam entre os $7 \%$ do rio Águeda e os $28 \%$ do rio Massueime. No Inverno, as perdas médias de caudal foram bastante expressivas, a variar entre os $30 \%$ e os $38 \%$, enquanto na Primavera assinalam maiores coeficientes de variação, entre os $15 \%$ do Rio Águeda e os $30 \%$ do rio Massueime. No Verão, a redução média de caudal foi especialmente sentida no rio Sabor, ao ver os seus escoamentos médios estivais baixarem para cerca de metade, enquanto no rio Massueime as perdas foram de $30 \%$ e no rio Beça de 19\%. O rio Águeda apresenta um comportamento inverso, assinalando um aumento de $19 \%$ no respectivo escoamento médio estival.

\subsection{Evolução diária dos caudais extremos}

Um dos aspectos mais interessantes, resultante da análise temporal dos caudais anuais e sazonais, prende-se com as mudanças detectadas no escoamento antes e após o inicio da década de 80. Com efeito, nas primeiras décadas observadas os caudais médios diários foram mais abundantes, assinalando importantes quebras quando comparados com os valores obtidos para o segundo período referido. No rio Sabor, o decréscimo rondou os $8,8 \mathrm{~m}^{3} / \mathrm{s}$, no rio Águeda os $3,6 \mathrm{~m}^{3} / \mathrm{s}$, no rio Beça os $2 \mathrm{~m}^{3} / \mathrm{s}$ e no rio Massueime foi de $0,7 \mathrm{~m}^{3} / \mathrm{s}$ (Quadro IV).

O confronto entre os valores médios anuais obtidos para o período estudado e a mediana mostram-se bastante distantes, realçando a parca representatividade do valor médio como elemento de caracterização dos caudais fluviais. De facto, a análise dos dados diários indicia a tendência para - predomínio de águas baixas, com caudais 10 vezes inferiores ao valor tido como médio, em grande 

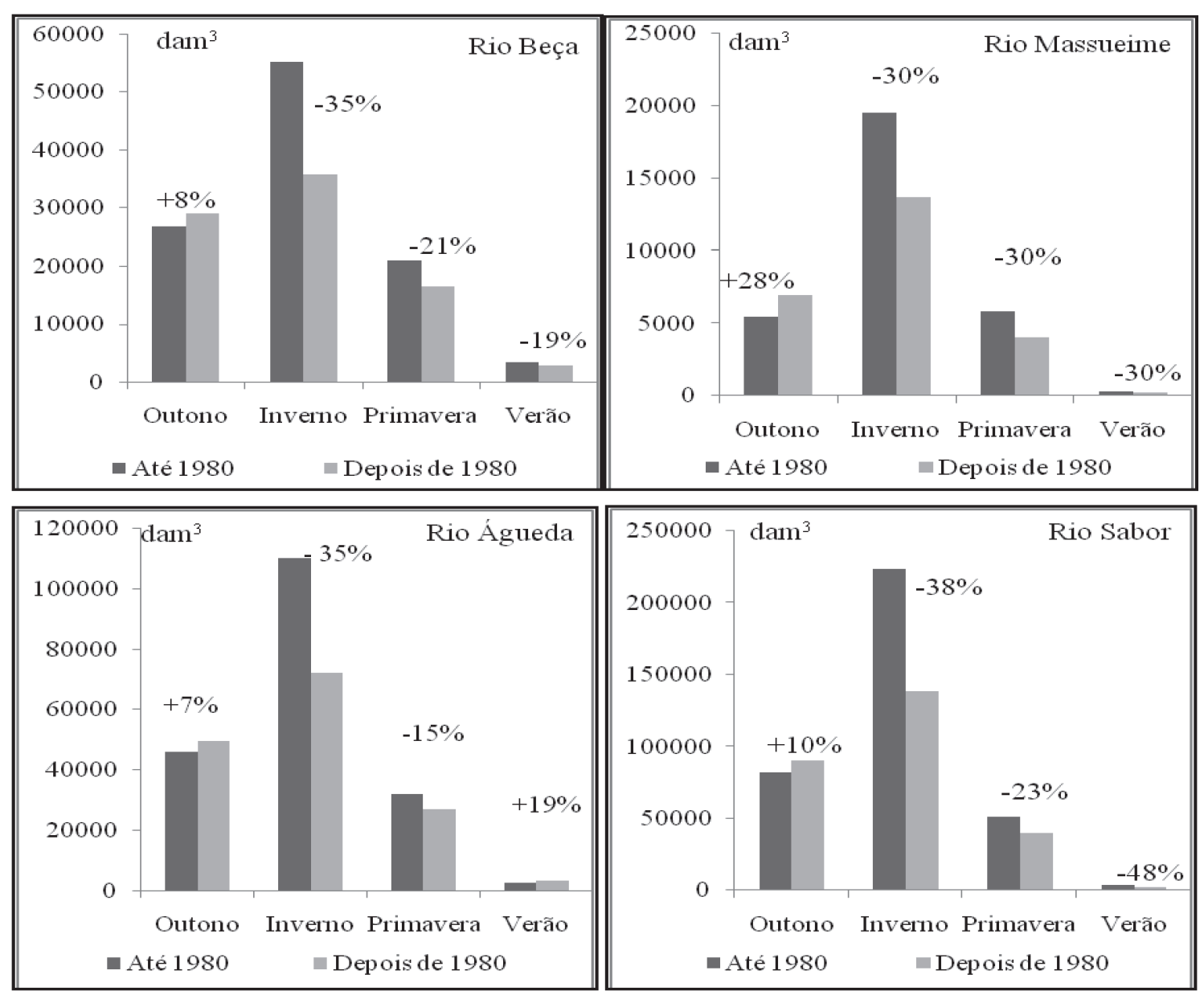

Figura 5 - Valores médios de escoamento, em dam³, nas diferentes estações do ano, antes e depois de 1980.

parte do ano, atingindo mais de 150 dias/ano no rio Massueime, 141 dias/ano nos rios Sabor e Águeda e 83 dias/ano no rio Beça. Em contrapartida, os caudais mais altos, neste caso 10 vezes superiores à média representam entre 3 e 6,5 dias/ano.

A distribuição dos caudais médios diários por percentil (Figura 6) corrobora os resultados anteriores e mostra que os valores mais altos, integrados ao último percentil, supõem $57 \%$ do total

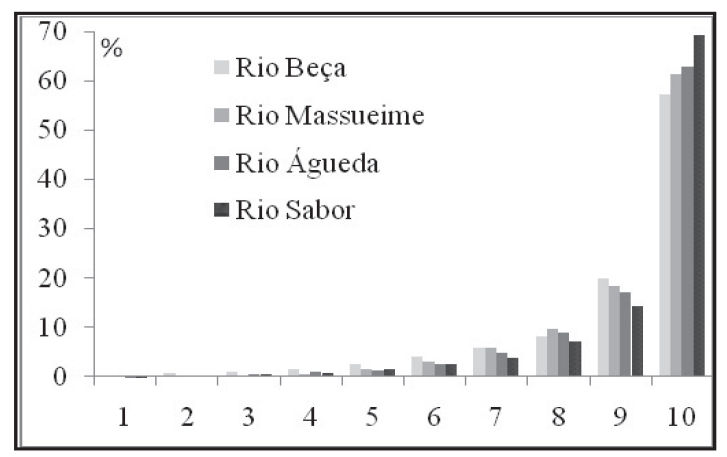

Figura 6. Distribuição dos caudais por percentil nas diferentes linhas de água, nos períodos hidrológicos analisados. de escoamento assinalado no rio Beça, $61 \%$ no Rio Massueime, 63\% no rio Águeda e 69\% no rio Sabor. A uma distância já significativa, situam-se os valores do nono percentil, os quais concentram entre $14 \mathrm{e}$ $19 \%$ dos totais de caudal. As restantes classes, e em particular as relativas aos 3 primeiros percentis, assinalam valores inferiores a $1 \%$ do total de caudais registados na série histórica de dados, correspondentes a cada um dos postos hidrométricos analisados.

A distribuição das frequências referentes aos máximos e aos mínimos diários de caudal, antes e após o inicio dos anos 80 sofre importantes variações, sobretudo quando se avaliam os dados referentes às águas baixas, as quais assinalam um incremento na sua representatividade em todas as bacias, no segundo período examinado (Quadro IV). O rio Beça apresenta as maiores discrepâncias, aumentando em cerca de 45 os dias com caudais de valores inferiores a 10 vezes a média. Contudo, nesta bacia ainda não se registaram dias com escoamentos nulos. Nos restantes tributários do Douro, o número médio de dias com águas baixas (< a 10 vezes a média) passou de 135 
RISCOS - Associação Portuguesa de Riscos, Prevenção e Segurança

Quadro IV. Valores médios, medianos, desvio-padrão e escoamentos máximos e mínimos, para a série histórica antes e após 1980.

\begin{tabular}{|c|c|c|c|c|c|c|}
\hline & & Unidades & $1950-2006$ & $\begin{array}{c}\text { Antes } \\
\text { de } 1980\end{array}$ & $\begin{array}{l}\text { Após } \\
1980 \\
\end{array}$ & $\begin{array}{c}\neq \text { Antes/ } \\
\text { após } 1980\end{array}$ \\
\hline \multirow{6}{*}{ 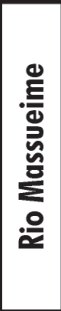 } & Média & $\mathrm{m}^{3} / \mathrm{s}$ & 2,7 & 3,0 & 2,3 & $-0,7$ \\
\hline & Mediana & $\mathrm{m}^{3} / \mathrm{s}$ & 0,6 & 0,7 & 0,5 & $-0,3$ \\
\hline & D. Padrão & $\mathrm{m}^{3} / \mathrm{s}$ & 6,1 & 6,6 & 5,5 & $-1,1$ \\
\hline & Escoam. 10 vezes $>$ média & Média de dias/ano & 4,3 & 4,4 & 4,2 & $-0,2$ \\
\hline & Escoam. 10 vezes $<$ média & Média de dias/ano & 152,7 & 148,4 & 156,3 & $+7,9$ \\
\hline & Escoamento nulo & Média de dias/ano & 66,7 & 50,8 & 80,8 & $+30,0$ \\
\hline \multirow{6}{*}{ 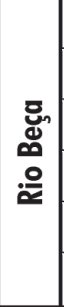 } & Média & $\mathrm{m}^{3} / \mathrm{s}$ & 9,1 & 10,0 & 8,0 & $-2,0$ \\
\hline & Mediana & $\mathrm{m}^{3} / \mathrm{s}$ & 3,9 & 4,4 & 3,1 & $-1,2$ \\
\hline & D. Padrão & $\mathrm{m}^{3} / \mathrm{s}$ & 16,7 & 17,5 & 15,6 & $-1,9$ \\
\hline & Escoam. 10 vezes $>$ média & Média de dias/ano & 2,9 & 3,4 & 1,8 & $-1,6$ \\
\hline & Escoam. 10 vezes $<$ média & Média de dias/ano & 83,2 & 63,1 & 108,3 & $+45,2$ \\
\hline & Escoamento nulo & Média de dias/ano & 0,0 & 0,0 & 0,0 & 0,0 \\
\hline \multirow{6}{*}{ 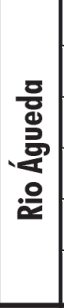 } & Média & $\mathrm{m}^{3} / \mathrm{s}$ & 16,1 & 18,1 & 14,5 & $-3,6$ \\
\hline & Mediana & $\mathrm{m}^{3} / \mathrm{s}$ & 2,8 & 3,1 & 2,5 & $-0,6$ \\
\hline & D. Padrão & $\mathrm{m}^{3} / \mathrm{s}$ & 38,4 & 40,8 & 36,5 & $-4,3$ \\
\hline & Escoam. 10 vezes $>$ média & Média de dias/ano & 5,3 & 5,6 & 5,3 & $-0,3$ \\
\hline & Escoam. 10 vezes $<$ média & Média de dias/ano & 141,5 & 129,6 & 150,3 & $+20,7$ \\
\hline & Escoamento nulo & Média de dias/ano & 1,9 & 0,0 & 3,3 & $+3,3$ \\
\hline \multirow{6}{*}{ 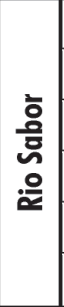 } & Média & $\mathrm{m}^{3} / \mathrm{s}$ & 22,6 & 33,7 & 24,9 & $-8,7$ \\
\hline & Mediana & $\mathrm{m}^{3} / \mathrm{s}$ & 5,7 & 6,5 & 5,0 & $-1,6$ \\
\hline & D. Padrão & $\mathrm{m}^{3} / \mathrm{s}$ & 89,2 & 98,3 & 82,7 & $-15,6$ \\
\hline & Escoam. 10 vezes $>$ média & Média de dias/ano & 6,5 & 7,7 & 5,0 & $-2,6$ \\
\hline & Escoam. 10 vezes $<$ média & Média de dias/ano & 141,3 & 135,2 & 148,4 & $+13,2$ \\
\hline & Escoamento nulo & Média de dias/ano & 12,6 & 5,1 & 27,2 & $+22,2$ \\
\hline
\end{tabular}

para 148 no rio Sabor, de 129 para 150 no rio Águeda e de 148 para 156 no rio Massueime, antes e após 1980, respectivamente.

Todavia, entre os dados mais relevantes cabe destacar a importante ampliação no número de dias sem escoamento, isto é com caudal nulo, observado no rio Massueime, ao passar em média de 51 dias/ano, antes da década de 80, para 81 dias/ano após esta data. Estes valores mostram que o número de dias marcados pela ausência de caudal praticamente duplicou, passando a estender-se por cerca de 3 meses. No rio Sabor, o curto período marcado por caudais nulos, cuja média se situava em 5 dias/ano no período de 1950/80, alongou-se de forma muito expressiva, afectando em média mais de 27 dias/ ano, após o inicio dos anos 80. O rio Águeda que desconheceu caudais nulos entre $1950-80$ passou a registar uma média de 3 dias/ano sem escoamento no ponto de monitorização analisado.

\section{Conclusões}

Os regimes dos rios estudados, pese embora a enorme diferenciação em termos de área drenada, manifestam comportamentos hidrológicos bastante similares. Reflectem as variações inter e intra-anuais da precipitação e, por conseguinte, observam importantes flutuações nas respectivas contribuições fluviais e nos caudais. Do mesmo modo, para o período hidrológico estudado manifestam uma diminuição no escoamento total anual, decréscimo esse, estatisticamente, significativo nos meses de Fevereiro e Março.

Em termos sazonais, com excepção do Outono no qual se verifica um incremento, todas as outras estações do ano manifestam tendências regressivas nos escoamentos observados, mais relevantes no Inverno e na Primavera, embora no Verão, dada a acentuada estiagem assinalada pelos rios analisados, e porque neste período ocorre um máximo 
de procura para consumos diversos, possam ocorrer situações de elevada precariedade em termos de recursos hídricos. Esta diminuição anual dos recursos e, sobretudo, em períodos em que se regista um máximo de procura (pela agricultura, turismo e consumo populacional devido ao regresso, para férias, de milhares de emigrantes) e um mínimo em termos de disponibilidade, deverá constituir matéria de reflexão a fim de evitar situações de insuficiência de água, como recorrentemente tem acontecido em determinadas áreas do nosso país, e que no futuro tenderão, decerto, a agravar-se se não forem tomadas medidas que visem uma planificação e uma gestão mais eficaz dos recursos hídricos.

Esta tendência declinante dos recursos hídricos superficiais, em particular a partir do inicio dos anos 80 , poderá dever-se a causas múltiplas, relacionadas com decréscimos na precipitação, dada a forte correlação que se estabelece entre estas duas variáveis, mas também poderá estar associada a outros factores, como por exemplo mudanças no uso e cobertura vegetal do solo. Com efeito, são múltiplos os autores que referem uma diminuição da precipitação no território continental português, em especial nestas últimas décadas (Alves, 1998; PORTELA e Quintela, 2000; Miranda et al., 2006). Esse decréscimo da precipitação ocorreu sobretudo na Primavera (de Março a Maio), ao mesmo tempo que se assinalam aumentos muito ligeiros nas restantes estações (Alves, 1998; MiRANDA et al., 2006).

Embora o factor climático seja importante na compreensão da hidrologia de uma região, para entender os recursos hídricos, relacionados com a produção de escoamento, não se pode desprezar o papel da respectiva área tributária, especialmente no que se refere ao uso do solo e respectiva cobertura vegetal. De facto, nas áreas em análise, à semelhança daquilo que ocorreu um pouco por todo o Interior Norte e Centro de Portugal, verificaram-se importantes alterações socioeconómicas, com consequências no uso e cobertura vegetal do solo (NUNEs et al., 2007).

O intenso êxodo rural operado desde a década de 50 do passado século, a terciarização das actividades económicas e o acentuado envelhecimento da população desencadearam importantes mudanças no uso do solo e coberto vegetal, com destaque para o abandono de vastas áreas agrícolas, nomeadamente as destinadas à cultura de cereais. $O$ abandono das terras, a par de um incremento no coberto vegetal pode contribuir para um aumento do consumo de água, ao mesmo tempo que a implementação de determinados usos do solo, ligados a culturas permanentes pode exigir mais recursos hídricos. Todavia, para se inferir sobre estas conexões é necessário aprofundar as relações entre estas variáveis e efectuar estudos de detalhe.

\section{Referências bibliográficas}

Alves, M. C. (1998) - "Os recursos hídricos e a possibilidade de mudança climática", 4- Congresso da Água, Lisboa.

Ayala-Carcedo, F. J. \& Iglesias lópez, A. (2000)"Impactos del Posible Cambio Climático sobre los Recursos Hídricos, el Diseño y la Planificación Hidrológica en la España Peninsula". In El Campo de las Ciencias y las Artes, Servicio de Estudios, Banco Bilbao-Vizcaya-Argentaria, no. 137, Madrid, Espanha, p. 201-222.

Beguería, S., López-Moreno, J.I., Lorente, A., Seeger, M., García-Ruiz, J.M (2003) - "Assessing the effect of climate oscillations and land-use changes on streamflow in the Central Spanish Pyrenees". Ambio, 32, p. 283-286.

Ceballos Barbancho, A. \& Morán Tejeda, (2005) "Evolución de las aportaciones hídricas en una cuenca de montaña del Sistema Central: cabecera fluvial del río Tormes (194 1-2004)". Cuadernos de Investigación Geográfica, 32, p.7-28.

Cunha, L. V., Ribeiro, L., Oliveira, R. P., Nascimento, J. (2006) - "Recursos hídricos". In F. D. Santos e P. Miranda (ed.), Alterações Climáticas em Portugal. Cenários, Impactos e Medidas de Adaptação. Lisboa, Gradiva Publicações, p. 115-168.

García-Ruiz, J.M., Beguería Portugués, S., López-Moreno, J.I., Lorente-Grima, A., SeEGer, M. (2001) - Los recursos hídricos superficiales del Pirineo aragonés y su evolución reciente. Logroño, Geoforma Ediciones, $191 \mathrm{p}$.

IPCC (2001)- Climate Change. Contribution of Working Group II to the Third Assessment Report of the Intergovernmental Panel on Climate Change, Cambridge, Cambridge University Press.

López Moreno, J. I, Beguería, S., García-Ruiz, J. M. (2003) - "Efecto de los embalses en el control de avenidas del Pirineo central español". Geographicalia, 44, p. 57-74.

Machín, J., Navas, A., Doménech, S., López-Vicente, $M$. (2005) -" El río Arlanza en cabecera: evolución 
reciente y tendencias en condiciones de cambio global". Cuadernos de Investigación Geográfica, 31 , p. 77-95.

Miranda, P. M. A., Valente, M. A., Tomé, A. R., Trigo, R., Coelho, M. F., Aguiar, A., Azevedo, E. B. (2006) - "O clima de Portugal nos Séculos XX e XXI". In F. D. Santos e P. Miranda (ed.), Alterações Climáticas em Portugal. Cenários, Impactos e Medidas de Adaptação. Lisboa, Gradiva Publicações, p. 45-113.

NUnes, A. (2007) - "Recursos hídricos na bacia do rio Côa: relações com a variabilidade climática e mudanças no uso do solo". In Territórios e Culturas Ibéricas II, Iberografias, 10, Lisboa, Ed. Campo das Letras, p.71-86.

Nunes, A., Figueiredo, A., Almeida, A. C. (2007) "Abandono agrícola no Interior Centro e Norte de Portugal: dinâmica da vegetação e impactes hidrogeomorfológicos". Actas do VI Congresso da Geografia Portuguesa, Universidade Nova de Lisboa, Lisboa, 23p.

Parry, M.L. (2000) - Assessment of Potential Effects and Adaptations for Climate Change in Europe: the ACACIA Project, Jackson Environment Institute, University of East Anglia.

PortelA, M. M. \& QuintelA, A. C. (2001) - "A diminuição da precipitação em épocas do ano como indício de mudança climática: casos estudados em Portugal continental". Ingeniería del agua, vol. 8, nㅡ 1 .

SNEYERS, R. (1992) - "Use and misuse of statistical methods for detection of climatic change". In: Climate Change Detection Project. Report on the Informal Planning Meeting on Statistical Procedures for Climate Change Detection. WCDMP 20. WMO.

Yue, S., Pilon, P.J., Cavadias, G., Phinney, B. (2002) "Power of the Mann-Kendal and Spearmans rho tests for detecting monotonic trends in hydrological series". Journal of Hydrology, 259, p. 254-271. 